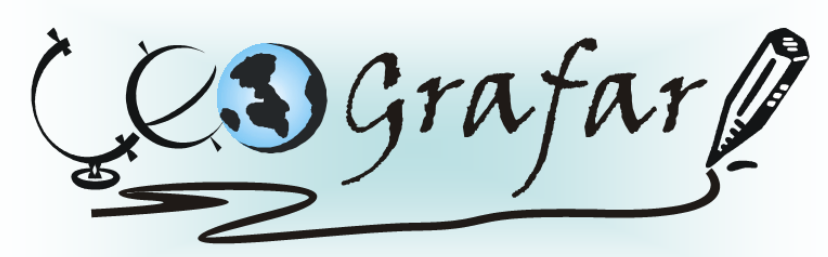

Revista Eletrônica do Programa de Pós-Graduação em Geografia - UFPR

\title{
REFLEXÕES EPISTEMOLÓGICAS SOBRE OS “TERRITÓRIOS DE IDENTIDADE”
}

\author{
CARLOS RITTER ${ }^{1}$
}

\section{RESUMO}

No Brasil e em grande parte da América Latina houve um aumento do uso dos termos território e identidade para nomear e para embasar projetos e programas governamentais voltados às suas áreas rurais. Dessa forma, julga-se válido proceder a uma reflexão com relação ao emprego desses termos, principalmente quando associados: Territórios de Identidade. Assim se estabelece um comparativo entre a teoria geográfica e as constatações empíricas relativas ao tema. Observa-se que as políticas atuais de desenvolvimento rural estão alicerçadas em concepções que trazem em seu escopo a tentativa de subestimar o componente "poder" e supervalorizar outros elementos, principalmente a "identidade", quando da definição e da delimitação do(s) território(s). Questiona-se, portanto, neste artigo, as definições conceituais de território e de Território de Identidade, bem como a tentativa de transformá-lo em uma unidade escalar de planejamento e de ação governamental.

Palavras-chave: Território, Identidade, Territórios de Identidade.

\section{EPISTEMOLOGICAL REFLECTIONS ON THE "TERRITORIES OF IDENTITY"}

\section{ABSTRACT}

In Brazil and much of Latin America has increased the use of the terms of territory and identity to name and to base projects and government programs aimed at addressing their rural areas. Thus, it was deemed valid to make a reflection regarding the use of these terms, especially when associated with: areas of Identity. Thus was established a geographical comparison between theory and empirical findings on the subject. It is observed that current policies for rural development are based on concepts that bring in scope to attempt to underestimate the component "power" and overvalue other elements, particulary the "identity", when the definition and delimitation of territory(ies). Wonders, therefore, in this article, the conceptual definitions of territory and the territory of Identity, and the attempt to transform it into a unit scale of planning and government action.

Keywords: Territory, Identity, Identity Territories.

\footnotetext{
${ }^{1}$ Aluno da pós-graduação em Geografia (UFPR) - carlos_ritter@hotmail.com
} 


\section{INTRODUÇÃO}

As políticas públicas brasileiras voltadas às áreas mais deprimidas socioeconomicamente sofreram certa guinada de orientação nas duas últimas décadas e passaram a contar com a presença marcante do terceiro setor, entre outras aparentes ações político-sociais, principalmente aquelas voltadas aos ambientes com características de ruralidade, com destaque para os períodos do segundo governo de Fernando Henrique Cardoso (1999-2002) e os dois de Luis Inácio Lula da Silva (2003-2006 e 2007-2010). Nesse contexto, elegeu-se para análise, um questionamento quanto à coerência do uso teórico e prático da terminologia "Territórios de Identidade".

Para tanto, após a apresentação do método utilizado, são abordados os resultados e as discussões, com destaque três reflexões:

- A primeira está voltada para o questionado e para o emprego conceitual de território, bem como a validade de sua diferenciação com relação ao conceito de espaço.

- A segunda para o conceito de identidade na Geografia e também na Antropologia, uma vez que o entendimento dispensado a esse termo nas políticas públicas recentes se aproxima do viés antropológico.

- Finalmente, a terceira reflexão é voltada para o objeto principal do artigo, os "Territórios de Identidade".

\section{MÉTODO}

Buscou-se enfatizar as questões epistemológicas e a "geograficidade"2 para o tema, dentre as múltiplas possibilidades de análise que ele permite. Num exercício praticamente dialético de confronto entre a teoria e as constatações empíricas próprias, obtidas nos estudos sobre as políticas públicas aplicadas ao espaço rural da porção Sul do Paraná e as presentes em alguns trabalhos científicos, relatórios, ensaios (constantes das referências bibliográficas) entre tantas produções já

\footnotetext{
2 Dardel (1990, p. 42) refere-se a uma geograficidade, no sentido de englobar as várias maneiras pelas quais o espaço pode ser entendido, seja pela sua "realização como lugar, como base e como meio".
} 
existentes, bem como o questionamento do emprego dos termos território e identidade é que se desenvolve o artigo.

Por se tratar de um trabalho com uma matriz geográfica, tem-se a consciência das limitações e das especificidades dessa ciência, sem, no entanto, desprezar ou não almejar a sua evolução. Sabe-se da sua grande necessidade de atualização teórica para dar conta do dinamismo dos acontecimentos contemporâneos, por essa razão, compartilha-se das multiplicidades pós-modernas que estão imprimindo à Geografia uma nova dinâmica e possibilitando flexibilidade epistemológica. Fatos que só estão se tornando possíveis graças às constantes reflexões e ao desejo de romper com as tradicionais amarras epistemológicas que cerceiam a sua renovação e a sua evolução conceitual-epistemológica.

\section{RESULTADOS E DISCUSSÕES}

No caminho da renovação e da evolução conceitual-epistemológica, rever e questionar o emprego conceitual para território e para identidade não é um trabalho em vão, principalmente quando esses termos estão nomeando projetos e programas, governamentais ou não, em andamento e que, a princípio, deveriam também embasá-los teoricamente. Dessa forma, com as reflexões desenvolvidas sobre os termos Território e Identidade, busca-se avaliar a coerência da junção realizada pela Secretária do Desenvolvimento Territorial do Ministério do Desenvolvimento Agrário para nomear as unidades de planejamento, estabelecidas no espaço rural brasileiro.

\subsection{TERRITÓRIO}

Trata-se de um dos conceitos mais relevantes para a Geografia Política, e de grande importância para as demais geografias. Nas últimas décadas ele vem causando embates quanto ao seu entendimento, pois aos poucos foi extrapolando a "exclusividade" que o restringia, na Geografia, ao domínio dos Estados, assim novas concepções epistemológicas Ihe foram atribuídas.

Nessa extrapolação, território passou, de certa forma, a ser confundido com espaço, como fez Haesbaert (2004) ao definir o espaço geográfico como quase 
sinônimo de território. No entanto, surgiram aqueles que passaram a defender a diferenciação e a dar preferência a um ou a outro termo. Como escreveu Sahr (2009), referindo-se aos "territoriólogos", como aqueles defensores e valorizadores dos territórios, contrapondo-os aos "espaciólogos" ${ }^{3}$ que atribuem maior destaque ao espaço:

Diante destas constatações, uma análise dos "territoriólogos" [...] revela uma situação curiosa. Sempre quando estes valorizam o "território", desvalorizam epistemologicamente o "espaço". Assim, por exemplo, Moraes aponta a vaguidade do conceito "espaço" [...]. Também Souza reduz o espaço a um "substrato" [...]. (SAHR, 2009, p. 147).

As discussões envolvendo o conceito território vêm se arrastando a um bom tempo na geografia brasileira, com Becker, 1983, 1995; Souza, 1988, 1995, 2006; Castro, 2005; Haesbaert, 1997, 2004, 2006; Saquet, 2007; Sahr, 2009, entre tantos outros, a partir de Ratzel, Raffestin, Lefebvre, Sack e demais contribuições ligadas a essa temática.

No entanto há aqueles que procuraram tangenciar esse questionamento, como Milton Santos e Rogério Haesbaert. Santos (1996, p. 194-196) não via "com bons olhos" o conceito "território", pelo fato de ele ser usado por atores hegemônicos em processos de apropriação com fins econômico-políticos, chegando a afirmar, em seu artigo, O papel ativo da Geografia: Um manifesto (2000), que a diferenciação entre território e espaço nada tem a acrescentar ao principal e verdadeiro debate substantivo. Santos assumiu, por essa razão, ter desistido de buscar uma distinção entre esses dois conceitos (espaço e território), salientando não existir território em si mesmo se não ocorrer a inclusão dos seus atores. Ainda, em 2001, em parceria com Silveira, escreve: "Por território, entende-se geralmente a extensão apropriada e usada" (SANTOS \& SILVEIRA, 2001, p. 19).

Haesbaert (2004, p. 61), por sua vez, deixa a impressão de que espaço é praticamente um "sinônimo de território" dependendo do enfoque, abstendo-se dessa forma de um posicionamento diferenciador para os termos, no entanto deixa uma importante contribuição ao admitir a presença de uma polissemia conceitual na

\footnotetext{
3 Souza (1986, p. 73) faz referência a "Espaciologia", proposta por Lefebvre e por Milton Santos, quase que simultaneamente, para qualificar a ciência do espaço, a qual envolveria não apenas geógrafos, mas também contaria com a participação decisiva de intelectuais de outras áreas.
} 
Geografia com relação ao termo território, ressaltando a dificuldade para se diferenciar as suas dimensões política e cultural (2001, p. 38).

Porém, um dos ápices desses questionamentos residiu em Souza (1988) com o artigo: Espaciologia - Uma objeção, com o qual abre um ciclo de constantes polemizações e instigações reflexivas com relação à questão espaço $x$ território, e depois (1995) dá continuidade ao embate com um novo artigo intitulado Território: sobre espaço e poder, autonomia e desenvolvimento, no qual são geradas críticas e uma grande polêmica, principalmente por reafirmar, nesse artigo, a célebre definição de que "todo espaço definido e delimitado por e a partir de relações de poder é um território"; ainda por recusar a visão positivista e "burguesa" de território, por dar uma aparente (falsa) impressão de reduzir o espaço a um "substrato"; e por destacar a existência de outras possibilidades de se constituir territorialidades por ações autônomas, como da prostituição, do tráfego de drogas, entre outras.

Entretanto, correntes divergentes dessa linha de pensamento, compartilhadas por Marcelo Lopes de Souza, investem num processo de desvalorização do componente "poder" na relação com o espaço, presentes nos territórios, tentando introduzir em seu lugar o elemento "identidade" como principal aglutinador e delimitador da sua existência.

Ora, "poder" e "identidade" não se opõem, pelo contrário tendem a se complementar e a se integrar, uma vez que toda identidade é socioculturalmente construída e permanentemente reconstruída pelos contextos, nas mais diversas escalas, a partir de valores herdados e da ação das forças hegemônicas, cujo objetivo principal é aglutinar, mobilizar, criar sinergias para a aceitação e para a legitimação das imposições coletivas e demais faces do poder. O poder, para ser estabelecido, necessita da decodificação das semiologias identitárias presentes para inferir, só assim, na reprodução e nas transformações das mesmas, numa relação dialética. Dessa forma, entende-se que todo território, ao ser estabelecido, passa a apresentar características identitárias e relações de poder espacializadas.

Desde a origem, o território nasce com uma dupla conotação, material e simbólica, pois etimologicamente aparece tão próximo de terra-territorium quanto de terreo-territor (terror, aterrorizar), ou seja, tem a ver com dominação (jurídico-política) da terra e com a inspiração do terror, do medo - especialmente para aqueles que, com esta dominação, ficam alijados da terra, ou no "territorium" são impedidos de entrar. Ao mesmo tempo, por extensão, podemos dizer que, para aqueles que têm o privilégio de usufruí- 
lo, o território inspira a identificação (positiva) e a efetiva "apropriação". (HAESBAERT, 2004, p. 94).

Nessa concepção, território é constituído com base nas relações de poder, mas não apenas ao tradicional "poder político-econômico", pois diz respeito tanto ao poder no sentido mais concreto e funcional, de dominação e/ou apropriação, quanto ao poder no sentido mais subjetivo, cultural/simbólico e/ou psicossocial, entre outras possibilidades.

Segundo Heidrich (2004, p. 56) "o conceito de território é essencial para se compreender as relações sócio-espaciais, pois a apropriação do espaço consiste na criação dos territórios, em duplo sentido de posse e adequação".

Desde o resgate do termo territorium, na antiguidade, já no fim do Império Romano, representando a hinterlândia de uma cidade subordinada ao Império, até as chamadas novas formas de territorialização apresentadas por Haesbaert (1995, 2004) entre outras, como territórios em rede, territórios flexíveis, territórios descontínuos e demais formas, percebe-se uma longa evolução histórica conceitual e material que acompanha o termo território de formas distintas pelo mundo.

Assim, compartilha-se do posicionamento do Sahr (2009, p. 149) ao afirmar que

[...] por isso não podemos geografar o conceito (território) apenas na sua horizontalidade atemporal (contexto atual e local), mas precisamos considerá-lo também na sua verticalidade temporal, ou seja, na evolução das suas forças formadoras.

Schneider (2009, p. 28-32), buscando novas referências para se pensar o desenvolvimento rural, resume em três paradigmas a maneira como o conceito de território vem sendo aplicado nos diferentes campos das ciências sociais.

No primeiro paradigma há uma tendência em definir território a partir das interações dos humanos com o espaço, pensando-o numa dimensão instrumental e normativa, no sentido de que um determinado lugar pode ser demarcado e apropriado. No segundo paradigma, pensa-o a partir das relações entre as dimensões imateriais, culturais e simbólicas. Neste, a questão central passa pela construção das identidades e da criação de códigos e normas regulatórias. No terceiro paradigma, ele é diretamente relacionado ao amplo campo dos estudos de 
economia. Nesta perspectiva, o conceito de território é associado ao de região, sendo muitas vezes tratado como sinônimo (novo regionalismo pós-fordista).

Dessa forma, constatam-se diferentes conotações e variações dos seus princípios quantitativos e qualitativos, tanto na teoria como na práxis; fatos que desconstroem os referenciais de um conceito unificador para o termo território.

\subsection{IDENTIDADE}

Num segundo momento dessa reflexão, faz-se necessário se voltar para o conceito de Identidade, não muito explicitado na "epistemologia geográfica", apesar de ser observado implicitamente nos trabalhos de Humboldt, Ritter, Ratzel, La Blache, entre outros, em descrições das características peculiares a certos povos, capazes de diferenciá-los dos demais. No entanto fica evidente que esses autores não objetivavam priorizar os aspectos identitários, e sim as características espaciais como um todo. Sauer e seus discípulos da Escola de Berkeley, entre outros, ao estabelecerem ligações mais acirradas com a antropologia e posteriormente com a sociologia, trouxeram para a Geografia uma "vertente cultural", da mesma forma o entendimento para identidade numa perspectiva relacional frente à alteridade, na qual o que se buscava estabelecer era a compreensão da identidade de um grupo diante do seu espaço, em interação entre as escalas regional, local, nacional, com relações de semelhança ou de igualdade.

Segundo Claval (2001), desde o final do século XIX, também foi percebido, na geografia francesa, um maior interesse pela questão sociocultural.

Di Méo et Buléon (2005, p. 44) afirmam que a identidade concerne tanto ao indivíduo como ao grupo, e que ela não é estranha à Geografia, muito pelo contrário, é observada há muito tempo, chegando os nomes dos grupos a serem confundidos com os nomes dos lugares.

Essa vertente cultural da Geografia, a partir da década de 1970, passa por um processo de renovação calcado principalmente no contexto da valorização da "cultura". Os geógrafos culturais passam a se preocupar não só com os aspectos considerados "materiais" da cultura, mas também com seus aspectos mais subjetivos e simbólicos. Isso se deve, principalmente, a um melhor entendimento e consequentemente uma maior valorização dos aspectos socioculturais. Nesse 
momento, o conceito de identidade passa a ser mais considerado no seio da Geografia, pelo menos das "geografias social e/ou cultural".

A identidade é construída a partir da interiorização de uma tradição, são afinidades que são estabelecidas transmitindo às pessoas que as vivenciam o sentimento de pertencer a determinados grupos sociais. A identidade pode basear-se na "idéia de uma descendência comum, de uma história assumida em conjunto ou de um espaço com o qual o grupo assume elos [...]. (CLAVAL, 2001: 179).

Haesbaert (2001), considerando a dimensão cultural do território, concebe-o como um espaço dotado de identidades, as quais são especificadas em "identidades territoriais". Dessa maneira, têm-se identidades territoriais e não territórios de identidade.

Bonnemaison \& Cambrèzy (1996, p. 10) afirmam que

O domínio do espaço territorial revela que esse espaço é cercado de valores não somente materiais, mas também éticos, espirituais, simbólicos e afetivos. É assim que o território cultural precede ao território político e ao espaço econômico. ${ }^{4}$

A maioria dos geógrafos restringe a existência da identidade ao campo das representações, contudo Haesbaert (1999, p.175) destaca a importância da base material para a construção das muitas identidades territoriais.

$\mathrm{Na}$ Antropologia, as discussões são mais antigas e mais aprofundadas com relação à(s) identidade(s). Sem muito derivar do campo geográfico, destacam-se as reflexões de Lévi-Strauss (1977, p. 16-17), propondo uma crítica ao próprio conceito de identidade, afirmando que a identidade não corresponderia a nenhuma experiência substantiva, mas seria um foco virtual, um esforço de construção indispensável à explicação, mas cuja existência seria puramente teórica. Apesar da grande radicalidade da separação entre modelo da identidade e experiência vivida, essa crítica fez avançar as reflexões antropológicas, segundo Monteiro (1997, p. 62), pelo fato de ter permitido retirar a noção de identidade do campo das essencialidades, obrigando-nos a pensá-la do ponto de vista relacional.

\footnotetext{
${ }^{4}$ Tradução livre do autor.
} 


\subsection{OS TERRITÓRIOS DE IDENTIDADE}

Ao retornar para o objeto principal - Os territórios de Identidade, percebe-se não tanto uma inadequação da ciência geográfica no sentido de compreender os atuais processos de desconstrução dos paradigmas de planejamento regional e a tentativa de construção das novas espacializações na América Latina, mas principalmente uma falta de posicionamento crítico com relação às políticas de elaboração e de implantação dos programas de "(re)ordenamento territorial" em voga no Brasil e em grande parte dos países latino-americanos.

Sahr (2009, p. 167) consegue sintetizar esse momento epistemológico para a Geografia, afirmando que "[...] o "território" dos geógrafos [...] é muito limitado e representa apenas mais uma territorialização, que eventualmente nem seja a mais importante da discussão".

Acredita-se que, por essa razão, o viés antropológico se apresenta como o mais interessante, encaixando-se nos desejos políticos reinantes do momento e, assim, passando a orientar a atual "compreensão territorial" a partir do enfoque cultural, e as consequentes políticas atinentes, principalmente, ao "espaço rural".

A questão da identidade, após chegar às instâncias jurídicas internacionais, passa também a integrar a nacional, principalmente no que tange às questões relacionadas ao "Desenvolvimento Sustentável" e às "Comunidades Tradicionais":

[...] em fevereiro de 2007, a Presidência da República adotou sua Política Nacional de Desenvolvimento Sustentável dos Povos e Comunidades Tradicionais [...] Agora, os povos e comunidades tradicionais considerados grupos culturalmente diferenciados e que se reconhecem como tais, que possuem formas próprias de organização social, que ocupam e usam territórios e recursos naturais como condição para sua reprodução cultural, social, religiosa, ancestral e econômica, utilizando conhecimentos, inovações e práticas gerados e transmitidos pela tradição (Art. $3^{\circ}$ ). Fala-se, neste momento, dos "territórios" como espaços (!) necessários à reprodução cultural, social e econômica dos povos e comunidades tradicionais, sejam eles usados de forma permanente ou temporária [...]" (grifos nossos) (SAHR, 2009, p. 155).

Percebe-se que por trás da adoção de novas estratégias para o enfrentamento das condições de desigualdades locais e regionais, com relação à deterioração sócio-ambiental, aos desníveis socioeconômicos e a baixa governabilidade, outros interesses, se fazem presentes nessas políticas. 
Passam a usar estratégias respaldadas numa territorialização restrita a uma aglutinação das identidades existentes, ou seja, a uma pretensa identidade social, para embasarem uma nova instância escalar de planejamento e ação - os Territórios de Identidade, diferente das escalas já testadas, como "microrregiões, microbacias hidrográficas, entre outras, e até mesmo tentando extrapolar a escala das municipalidades.

\begin{abstract}
A produção de identidade coletiva, seja de natureza social ou geográfica [...], é também uma ferramenta poderosa, a serviço do poder. Assim, a territorialidade restrita a uma identidade social facilita exercer um controle político sobre o grupo que a compartilha. Ela também reforça a hegemonia e a dominação sobre o espaço social em questão. [...] Produzir identidade coletiva geralmente significa fabricar um mito mobilizador que fortalece a imagem do grupo territorializado como um todo unificado, além de suas divisões reais. (DI MÉO et BULÉON, 2005, p. 45)
\end{abstract}

O que parece novo ou até mesmo "revolucionário" num primeiro momento, após uma análise historicizada/contextualizada, revela, de certa forma, não passar de um "continuísmo da dependência" 6 . Os Territórios de Identidade exemplificam, mais uma vez, a já conhecida influência exógena na América Latina com modelos de planejamento e de desenvolvimento regional/“territorial” bem sucedidos, oriundos da Europa ou dos EUA, principalmente, sendo trazidos para cá no intuito de, quando implantados, reproduzirem o mesmo êxito alcançado nos seus locais de origem, desconsiderando, na maioria das vezes, as especificidades locais. O LEADER ${ }^{7}$ na consolidação da União Européia e as experiências da $3^{\text {a }}$ Itália ${ }^{8}$ bem exemplificam tal situação.

\footnotetext{
${ }^{5}$ Tradução livre do autor.

${ }^{6}$ Ver a A Teoria da Dependência - uma formulação teórica desenvolvida por intelectuais como Ruy Mauro, Mauro Marini, André Gunder Frank, Theotonio dos Santos, Vania Bambirra, Orlando Caputo, Roberto Pizzaro entre outros, consistindo em uma leitura crítica e marxista não dogmática dos processos de reprodução do subdesenvolvimento na periferia do capitalismo mundial, em contraposição às posições marxistas convencionais ligadas aos partidos comunistas ou à visão estabelecida pela CEPAL.

O LEADER - "Ligações Entre Ações do Desenvolvimento da Economia Rural"-programa implantado nos países da União Européia, a partir de 1991, fazendo parte da Política Agrícola Comum (PAC). Visou romper parcialmente com os paradigmas de desenvolvimento rural reinantes até então, passando a reconhecer e valorizar o caráter multifuncional e as potencialidades locais do espaço rural europeu (Leader I, II e Leader +).

${ }^{8}$ Refere-se aos projetos implantados no centro e no noroeste da Itália, com a formação de redes de pequenas empresas e de aglomerações setoriais de empresas com fortes ligações com o meio sócio territorial. A presença e a consolidação das capacitações tecnológicas endógenas próprias de cada região asseguravam uma efetiva participação de pequenos e médios empreendimentos,
} 
Esses modelos foram inspiradores de projetos em uma América Latina ainda conturbada pela conjuntura de mudanças políticas, com a substituição das ditaduras militares pelas populistas, exageradamente denominada de "democratização"; pelas suscetibilidades às "novas" da globalização, para as quais o modelo de desenvolvimento, principalmente rural, mostrou-se ineficiente. Por essa razão, tido como esgotado, e, ainda, onde predominam estruturas e conjunturas de uma herança colonial, com marcas evidentes de clientelismo, de concentração excessiva da posse da terra, até mesmo de trabalho "subescravo", entre outros.

Perico (não datado), chefiando uma equipe do Instituto Interamericano de Agricultura (IICA), no relatório de uma pesquisa encomendada pela Secretária do Desenvolvimento Territorial do Ministério do Desenvolvimento Agrário (SDT do MDA) do Brasil, sobre as tipologias territoriais, escreve que os Territórios de Identidade no Brasil estão sendo criados/conformados a partir de uma proposta inovadora de Desenvolvimento Territorial, elaborada pela SDT do MDA. Tidos como eixo constitutivo da uma estratégia geral de desenvolvimento rural, articulada aos processos de desenvolvimento sustentável, à formação de capacidades, à gestão social, à articulação de políticas e à dinamização econômica, seguindo os seguintes passos:

- fase de regionalização, tendo por base as microrregiões homogêneas (IBGE) as quais obedecem critérios ambientais, econômicos, sociais e institucionais. A SDT pautou-se em 556 microrregiões pelo fato de ser esse um critério compartilhado por vários ministérios e programas públicos.

- Fase de seleção, utilizando dois pontos básicos: número de habitantes (com até 50.000) e a densidade demográfica inferior a 80 habitantes por hectare, somados ao grau de ruralidade(? $)^{9}$. Isso resultou na seleção de 449 microrregiões rurais. Dessas foram selecionadas aquelas com maior presença relativa de unidades de produção familiar em até quatro módulos fiscais, locais de famílias assentadas pelo INCRA, de famílias acampadas e

promovendo uma ligação intensa entre as empresas e o local, gerando expansão da capacidade competitiva (GURISSATTI, 1999).

O desenvolvimento dos distritos industriais italianos, fundados em redes de pequenas e médias empresas, foi tão intenso a partir de 1970 que ganharam o status de "modelo".

${ }^{9}$ A SDT não define e nem estabelece quais seriam os parâmetros para o que seria ruralidade. 
as de mais baixos IDH. Incluindo pelo menos uma microrregião de cada estado da Federação.

- Fase da inclusão identitária- esse fato, segundo Perico (sem data) mudou a definição e a seleção inicial das microrregiões em favor dos territórios. A identidade, referida ao território, deveria se expressar como uma territorialidade através de um sentimento político, de uma energia social e uma vontade coletiva.

Ainda, nesse mesmo relatório, esse autor apresenta como significado metodológico do enfoque territorial a visão integradora de espaços, atores sociais, mercado e políticas de intervenção pública, com a perspectiva de se obter geração de riquezas e equidade redistributiva, respeitando a diversidade, a solidariedade, a justiça social e a inclusão socioeconômica e política. Dessa forma, cita quatro aspectos que justificariam a abordagem territorial como referência para as estratégias de apoio ao desenvolvimento rural:

1. O rural é mais do que o agrícola;

2. A escala municipal é restrita e inadequada;

3. A escala estadual é muito ampla; e

4. O território é a unidade que melhor dimensiona os laços de proximidade entre as pessoas, os grupos sociais e as instituições que possam ser mobilizados.

\section{CONCLUSÃO}

Julga-se um pouco utópico o significado metodológico apresentado no relatório da pesquisa sobre tipologias territoriais realizado pelo IICA-Brasil, por solicitação da SDT do MDA (não datado), e ao, mesmo tempo, constata-se grandes dificuldades para se colocar em prática tais ações, uma vez que apresentam alguns elementos etéreos.

Nesse contexto, entre as dificuldades enfrentadas pelos Territórios de Identidade, destaca-se o fato de eles não possuírem status político-administrativo, não constituírem unidade consolidada de planejamento, de participação e muito menos de gestão, e se manterem atrelados aos municípios com relação a uma série de ações administrativas, como para o repasse de verbas, entre outras. Para exemplificar, a via orçamentária se dá do MDA para a SDT, dessa para os 
municípios e não para os Territórios de Identidade, portanto, esses territórios ficam dependentes das administrações municipais.

Todavia, para esta reflexão, na essência epistemológica, procurou-se enfatizar o emprego dos termos território e identidade, bem como o confronto com as constatações práticas observadas. Nesse intuito, questionam-se os critérios para se identificar e se espacializar a "identidade de um território" ou então o "território de uma determinada identidade". Enfim, como delimitar para fins práticos um irreal espaço homogêneo em uma configuração de crescente heterogenia, e como materializar o "território" como uma unidade escalar de planejamento e de ação para políticas de médio e longo prazo, quando os caminhos reflexivos apontam para uma multiterritorialidade.

Pelo posicionamento já exposto com relação aos entendimentos conceituais dos termos em questão, julga-se que há mais pluralidades do que singularidades no espaço rural brasileiro; que os territórios se apresentam cada vez mais efêmeros e mutantes, não permitindo, dessa forma, encontrar identidade e sim identidades em constante processo de (re)construção. Mesmo nas comunidades chamadas tradicionais, o que se observa, na contemporaneidade, são as complexidades interativas espaço-temporais e as crescentes ondas de influência externa responsáveis pela formação de variadas territorialidades.

\section{REFERÊNCIAS}

BECKER, B. O uso político do território: questões a partir de uma visão de terceiro mundo. In BECKER, B. et al. (orgs) Abordagens políticas da espacialidade. Rio de Janeiro: UFRJ, 1983, p. 1-21.

A geopolítica na virada do milênio: logística e desenvolvimento sustentável. In: CASTRO, I. E. de, GOMES, P. C. da C.,CORREAA, R. L. (orgs). Geografia: Conceitos e temas. Rio de Janeiro: Bertrand, 1995, p. 271-308.

BONNEMAISON, J. e CAMBRĖZY, L. Le lien territorial: entre frontières et identités. Géographies et Cultures. Le Territoire, n. 20. Paris: L`Harmattan, 1996.

CASTRO, I. E. de. Geografia e política: território, escalas de ação e instituições. Rio de Janeiro: Bertrand, 2005.

CLAVAL, P. A geografia cultural. 2. ed. Florianópolis: Ed. da UFSC, 2001. 
DARDEL, E. L`homme et la terre. Paris: ETHS, 1990.

DI MÉO, G. e BULÉON, P. L`Espace social. Une lecture géographique de sociétes. Paris: Armand Colin, 2005.

GURISATTI, P. O Nordeste Italiano: nascimento de um novo modelo de organização industrial. In: COCCO et al. (orgs.). Novos territórios produtivos e políticas públicas: o caso da Terceira Itália. Rio de Janeiro: DPA, 1999.

HAESBAERT, R. Des-territorialização e identidade: a rede "gaúcha" no Nordeste.Niterói: UFF, 1997.

Identidades territoriais. In: CORRÊA, R. L. e ROSENDHAL, Z. (orgs).

Manifestações da Cultura no Espaço. Rio de Janeiro: EdUERJ, 1999.

Desterritorialização: entre as redes e os aglomerados de exclusão. In: CASTRO, I. E. de et al. Geografia: Conceitos e Temas. 3. ed. Rio de Janeiro: Bertrand Brasil, 2001, p. 165-205.

O Mito da Desterritorialização - "Do fim dos territórios à Multiterritorialidade". Rio De Janeiro: Bertrand Brasil, 2004.

Territórios alternativos. São Paulo: Contexto, 2006.

HEIDRICH, A. L Território, integração socioespacial, região, fragmentação e exclusão social. In: RIBAS, A. D.; SPOSITO, E. S.; SAQUET, M. A. (orgs.). Território e desenvolvimento: diferentes abordagens. Francisco Beltrão: UNIOESTE, 2004. p. 37-66

LÈVI- STRAUSS, C. L’ Identité. Paris: Grasset, 1977.

MONTEIRO, P. Globalização, Identidade e Diferença. Novos Estudos CEBRAP, № 49, novembro1997, p. 47-64.

PERICO, R. E. (e equipe). Identidade e território no Brasil. Relatório da pesquisa sobre tipologias territoriais realizado pelo IICA-Brasil, por solicitação da SDT do MDA, não datado.

SAHR, W-D. Territórios-Faxinais-Espaços. A problemática "Espaço/Território" na formação social brasileira. In SAQUET, M. A. e SPOSITO, E. S.(orgs) Territórios e Territorialidades. Teorias, processos e conflitos. 1. ed. - São Paulo: Expressão Popular: UNESP- Programa de Pós-Graduação em Geografia, 2009.

SANTOS, M. A Natureza do Espaço: tempo e técnica - razão e emoção. São Paulo: Hucitec, 1996.

et al. O papel ativo da Geografia: Um manifesto. Florianópolis: XII Encontro Nacional de Geógrafos, 2000. 
Por uma outra globalização. Do pensamento único à consciência universal. Rio de Janeiro: Record, 2001.

SANTOS, M. e SILVEIRA, M. L. O Brasil: território e sociedade no início do século XXI. São Paulo: Record, 2001.

SAQUET, M. Abordagens e concepções de território. São Paulo: Expressão Popular, 2007.

SCHNEIDER, S. Ciências Sociais, Ruralidade e Territórios: em busca de novas referências para pensar o desenvolvimento. In: revista de geografia agrária CAMPOTERRITÓRIO, v.44, n. 7, p. 24-62, fev. 2009.

SOUZA, M. L. de. "Espaciologia": Uma objeção (Crítica aos prestigiamentos pseudocríticos do Espaço Social), Terra Livre, São Paulo, v. 5, 1988, p. 21-46.

O Território: sobre espaço e poder, autonomia e desenvolvimento. In:

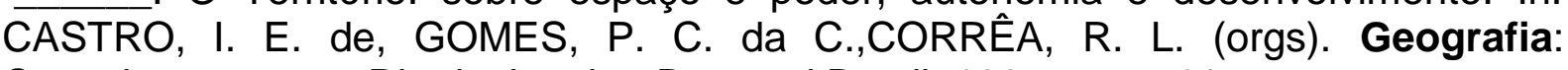
Conceitos e temas. Rio de Janeiro: Bertrand Brasil, 1995. p. 77-115.

A prisão e o ágora: reflexões em torno da democratização do planejamento e da gestão das cidades. Rio de Janeiro: Bertrand Brasil, 2006.

" "Território" da Divergência (e da confusão): em torno das imprecisas fronteiras de um conceito fundamental. In: Territórios e territorialidades: teorias, processos e conflitos. (orgs) SAQUET, M. A. e SPÓSITO, E. S. 1. ed. São Paulo: Expressão Popular: UNESP, 2009.

(Recebido em 15.07.2010. Aceito em 02.04.2011) 